\title{
Adaptive Immunity from Prokaryotes to Eukaryotes: Broader Inclusions Due to Less Exclusivity?
}

\author{
Edwin L. Cooper \\ Laboratory of Comparative Neuroimmunology \\ Department of Neurobiology, David Geffen School of Medicine at UCLA \\ University of California, Los Angeles \\ USA
}

\section{Introduction}

\subsection{The prevailing view: blurring, innate and adaptive}

The currently held view of the immune system proposes generally acceptable descriptions supported by strong evidence. There are two primary systems: innate and adaptive but distributed "unequally" among the two major animal groups (ignoring mostly all plants). Animal groups include the multitudinous invertebrates and vertebrates with vertebrates being the greatest beneficiaries of a fully functional complex immune apparatus that combines the two systems. Despite this super armamentarium, the overwhelming problems of possessing this dual system, as the vertebrates i.e. the innate and adaptive does not seem to guard or even prevent the development of one internal threat to survival. This is the scourge: development of cancer. By contrast invertebrates whose immune system is primarily of the innate type manage to eat, reproduce and survive without developing cancer. Briefly the immune system consists of: Innate: natural, nonspecific, no memory, nonanticipatory, non-clonal, germ line; Adaptive: acquired, specific, memory, anticipatory, clonal, somatic. In general, both systems and in the simplest reductionist terms, each must possess a cell that recognizes an antigen and digests it. The second cell if appropriately stimulated must react to destroy a potentially detrimental antigen. During evolution more cells were added to this armamentarium giving rise to increasing functions associated with effector activity. Emerging information supports the view that overlap or blurring exists between these two sometimes rigidly defined systems. Clearly evidence suggests that lines of demarcation within and between innate and adaptive may not be so strictly delineatedthere is immunologic flexibility designated as blurring, not "black and white".

\subsection{Evolution of the immune systems}

\subsubsection{The agnathans (jawless fish)}

We have been alerted to numerous analyses of the vertebrate and more specifically the mammalian immune system that reveal profound interrelationships and fundamental differences between the adaptive and innate systems of immune recognition (Fig.) [Du 
Pasquier and Litman, 2000]. There is increasing experimental accessibility of nonmammalian jawed vertebrates (gnathosomes; cartilaginous and bony fish), jawless vertebrates (agnathans) (hagfish, lampreys), protochordates and invertebrates and an enthusiasm by comparative immunologists to explore. Thus we have intriguing new information that suggests likely patterns that reveal emergence of immune-related molecules during metazoan phylogeny. Moreover there is the promise that we may find evolution of alternative mechanisms that ensure receptor diversification. These such findings have already blurred traditional distinctions between adaptive and innate immunity. The adaptive must rely on the innate throughout evolution, the immune system has benefited by using a remarkably extensive variety of well-equipped mechanistic solutions to meet fundamentally similar requirements for host protection.

The range of such molecules, which includes the fibrinogen-related proteins (FREPs) in a mollusk, variable regioncontaining chitin-binding proteins (VCBPs) in a cephalochordate, variable lymphocyte receptors (VLRs) in jawless vertebrates, and novel immune-type receptors (NITRs) in bony fish, encompasses both the immunoglobulin gene superfamily (IgSF) and leucine-rich repeat (LRR) proteins. Although these molecules vary markedly in form and likely in function, growing evidence suggests that they participate in various types of host immune responses. These results represent significant alternatives to prevailing paradigms of innate and adaptive immune receptors. Thus unusual genetic mechanisms may support mechanisms for diversifying recognition proteins and it may be a ubiquitous characteristic of animal immunity (Fig. 2) (Theodor, 1970; Hildemann et al, 1977; Franc et al, 1996; Pancer, 2000; Watson et al, 2005; Sun et al, 1990; Flajnik and Pasquier, 2004; Zhang et al, 2004 ), not restricted rigidly to innate and adaptive.

Our immune system rarely acts alone but functions in association with the other two linked regulating systems (the nervous and endocrine systems; not to be examined in this review). Second, when we examine the immune systems close up, there are several generalizations that emerge. The immune system is ubiquitous, found in all creatures including plants and is therefore not restricted to humans. If carefully traced stepwise during evolution treating extremely limited fossil forms, reveals progressively more complex development after we critically examine various levels of plant and animal evolution. There is evidence for innate immunity in plants. According to Luke and O'Neill (2011), “Every organism has to contend with the risk of infection. To cope, organisms have evolved two types of immune responses: the more recent "adaptive" system, found only in vertebrates; and the more ancient "innate" system, which is present in both plants and animals. Researchers have uncovered remarkable evolutionary conservation of innate immune mechanisms between plants and animals. (Figure 3) They use similar receptor molecules to sense pathogens and for immune system signaling (Luke and O'Neill 2011).

This review will: 1) for the first time present an emerging view that "adaptive immunity" mechanisms need not be restricted to complex eukaryotic organisms. Although this may be revolutionary, we might ask: why not since microbes survive? In fact, there is compelling information that prokaryotes may possess adaptive immune mechanisms; 2) deemphasize the over reliance on embryologically defining the animal kingdom and forcing the immune system's evolution into two separate categories, i.e. the protostomes and deuterostomes; 3) support concepts that propelled the immune system into prominent discourse in the life 
sciences; 4) indicate that the concern for immunologic memory, development of cancer, autoimmunity, and clonal selection may not be essential for effective immunity to evolve; 5) consider analogous mechanisms in prokaryotes that concern CRISPR that are direct repeats found in the DNA of many bacteria and archaea; 6) to understand the mechanism of action of CRISPR systems reveals a prokaryotic analog of eukaryotic RNA supporting the view that bacteria possess a form of acquired immunity; 7) suggest a molecular mechanism by which the nervous system may sense inflammatory responses and respond by controlling stress response pathways at the organismal level; This supports the interconnectedness of two of the three monitoring systems: immune<>nervous $<>$ endocrine to maintain a balanced internal milieu.

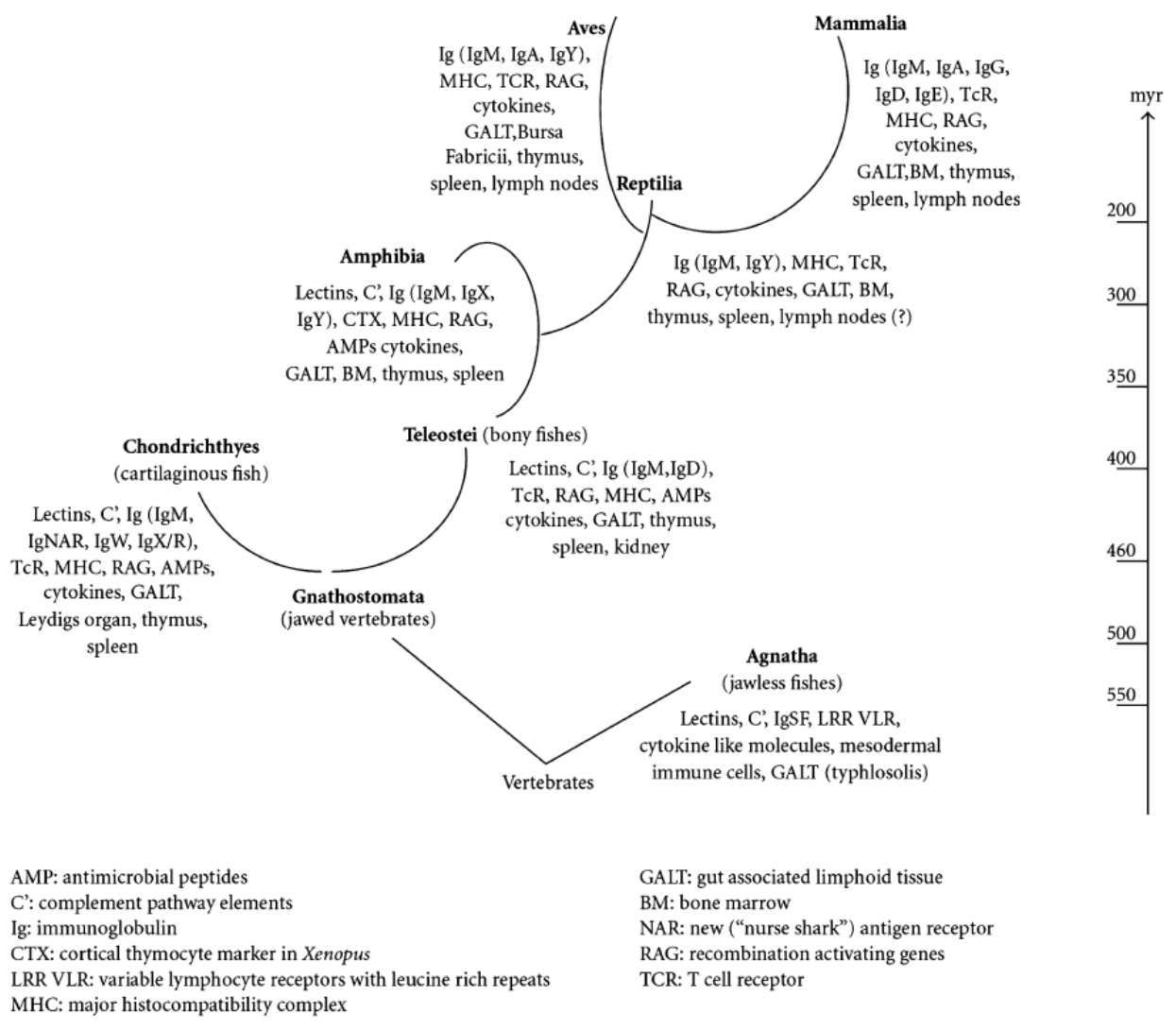

Fig. 1. Evolution of molecular and histological structures of the vertebrate immune system. Regarding lymphatic tissues, the thymus, and spleen appeared early in fishes, while lymph filtering lymph nodes are observed only in birds and mammals. Among the development of various immunoglobulin isotypes, IgD is expressed in bony fishes, later only mammals are using this B-cell receptor. Reproduced by permission from (Kvell K, Cooper EL, Engelmann P, Bovari J, Nemeth P. Blurring borders: Innate immunity with adaptive features. Clin Dev Immunol (2007):836-71). 


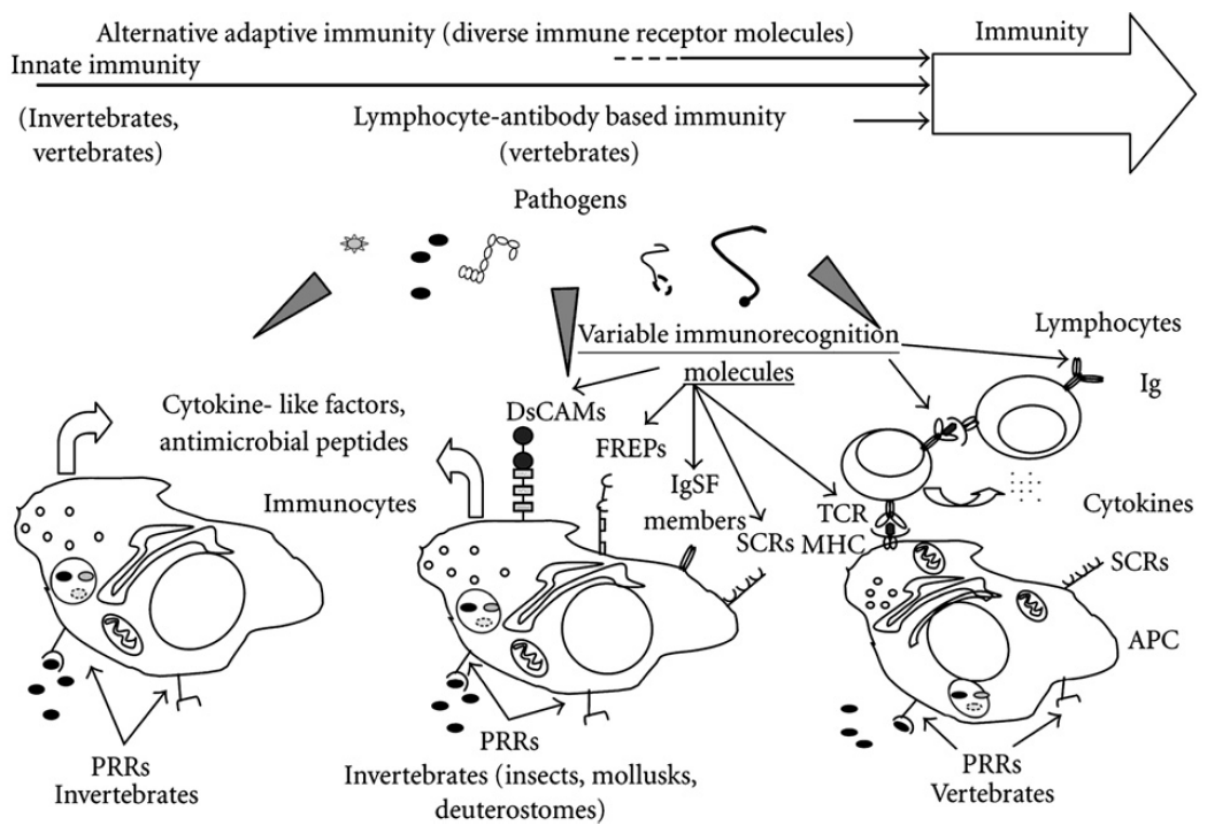

Fig. 2. Schematic representation of innate and adaptive immune feature development in animals. All immune cells express nonspecific receptors, for example, pattern recognition receptors that recognize pathogen associated molecular patterns (PAMPs). Several clusters of innate receptors are conserved from plants to humans and are essential components in the defense of self-integrity. Immune cells of invertebrates also express various scavenger receptor-like proteins (Croquemort, SCRs), immunoglobulin superfamily members (hemolin, DsCAM), and fibrinogen-related peptides (FREPs); all involved in immune functions (eliminating apoptotic cells, parasites, etc.). Invertebrate immune systems also exhibit receptors with high diversity involved in immune functions: FREPs, SCRs, and DsCAMs have extreme individual variability-like vertebrate adaptive immune recognition molecules (Ig, TcR). Reproduced by permission from (Kvell K, Cooper EL, Engelmann P, Bovari J, Nemeth P. Blurring borders: Innate immunity with adaptive features. Clin Dev Immunol (2007):836-71).

\subsection{Self/ not-self}

Now Self/not self, adaptive immunity and a fresh and renewed vision of a vigorous innate immunity are acceptable first for invertebrates and now essential for mammals. However, self/not self is now challenged by the controversial, alternative danger hypothesis. (Cooper, 2010; Cooper et al, 2002; Engelmann and Nemeth, 2010; Cossarizza, 2010; Parrinello 2010 Pradeu and Carosella 2004; 2006). Since Metchnikoff discovered phagocytosis, controversy persisted concerning two points. First, innate immunity was accorded minor significance to most of immunology while adaptive immunity emerged as predominant, perhaps due to anthropocentricity of 19th and early 20th century immunologists. Later adaptive immunity acquired a significant hypothetical base. Second, clonal selection and specific memory cast a 
shadow over Metchnikoff's leukocytes, perhaps bolstered by discovering them in invertebrates and not in mammals (Cooper, 2008; Cooper 2010)

Pradeu and Carosella criticize origins and legitimacy of self/non-self. They advocate a critical analysis both conceptually and experimentally to redefine self/non-self that reveals certain shortcomings; they even advocate possibly rejecting that model in favor of an alternative theoretical view for immunology: continuity. The 'continuity hypothesis' attempts to support immunogenicity that avoids criticism of the self-model. Pradeu and Carosella assert that the main objective of immunology is to establish why (teleological?) and when an immune response occurs: to support immunogenicity. Is there an experimental model?

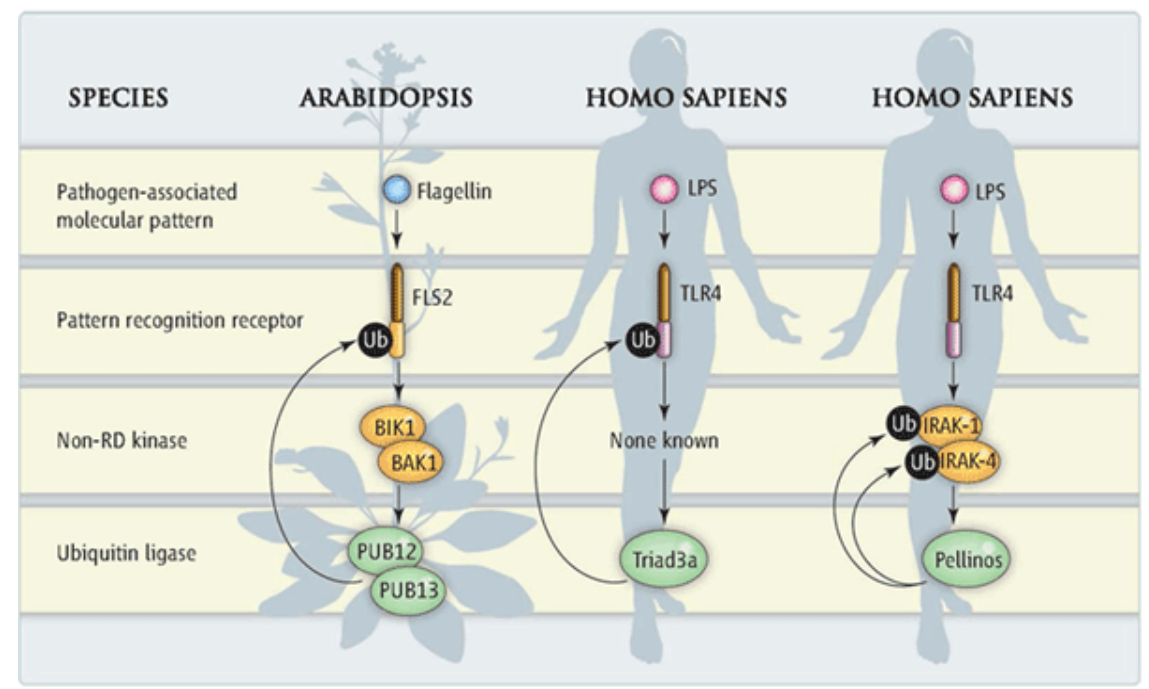

Fig. 3. Innate immunity, conserved.

Arabidopsis and humans have evolutionarily conserved innate immune signaling processes that involve a posttranslational modification process called ubiquitination. In Arabidopsis, bacterial flagellin is sensed by FLS2, which recruits the non-arginine/aspartate (Non-RD) kinases BAK1 and BIK1. BAK1 phosphorylates and activates PUB12/13, which ubiquitinates (Ub) FLS2 and leads to degradation. In humans, TLR4 senses lipopolysaccharide (LPS). This can activate Triad3a (third column), which ubiquitinates TLR4 and leads to its degradation. TLR4 can also activate IRAK-1 and IRAK-4 (fourth column), which activates nuclear factor kappa B (not shown), and also Pellino proteins (Pellinos), which ubiquitinate the IRAKs and lead to their degradation.

\subsection{Clonal selection}

Another view pertinent to prevailing immunologic concepts includes clonal selection which is a Darwinian corollary. In other words lymphocytes with appropriate receptors could be stimulated to divide leaving progenitor offspring lymphocytes. Now we may be able to deconstruct clonal selection since it may be not applicable to invertebrate mechanisms; all evidence indicates that clonal selection is purely a vertebrate strategy. Some views may 
insist that anthropocentric mammalian immunologists utilized a tool to propel: the universal innate immune system of ubiquitous and plentiful invertebrates as an essential system for vertebrates. Immunology benefited and innate immunity acquired an extended raison d'être. Innate immunity should help if there is a failure of the adaptive immune system. As an internal threat cancer would be subject to the immune system's efficiency. Still to be answered are questions concerning immunologic surveillance that includes clonal selection. According to the question does immunologic surveillance play a role in the survival of invertebrates that seem to not develop cancer as we identify metastasizing transplantable vertebrate type? As a possible explanation, perhaps invertebrate efficient innate immune systems and short life spans evolved certain "canceling devices" that maintain survival, thus precluding their demise by metastasis. (Cooper et al, 2002; Burnet, 1959; Burnet 1962)

\section{Phylogenetic Tree of Life}

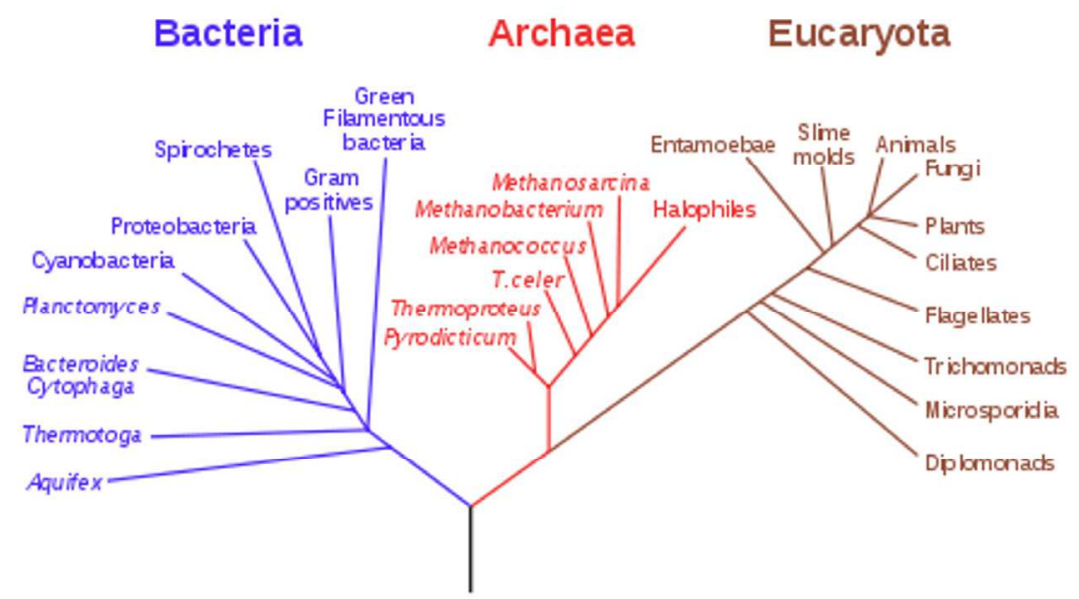

Fig. 4. A phylogenetic tree of living things, based on RNA data and proposed by Carl Woese, showing the separation of bacteria, archaea, and eukaryotes. Trees constructed with other genes are generally similar, although they may place some early-branching groups very differently, thanks to long branch attraction. The exact relationships of the three domains are still being debated, as is the position of the root of the tree. It has also been suggested that due to lateral gene transfer, a tree may not be the best representation of the genetic relationships of all organisms. For instance some genetic evidence suggests that eukaryotes evolved from the union of some bacteria and archaea (one becoming an organelle and the other the main cell). Author : Eric Gaba. Published : Sep. 2006. Nasa Astrobiology Institute. http://en.wikipedia.org/wiki/File:Phylogenetic_tree.svg

\section{What are prokaryotes?}

It is essential to define prokaryotes. The prokaryotes are a group of organisms that lack a cell nucleus (= karyon), or any other membrane-bound organelles. The organisms that have 
a cell nucleus are called eukaryotes. (Figure 4) Most prokaryotes are unicellular, but a few such as myxobacteria have multicellular stages in their life cycles. The word prokaryote

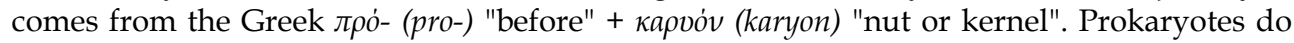
not have a nucleus, mitochondria, or any other membrane-bound organelles. In other words, neither their DNA nor any of their other sites of metabolic activity are collected together in a discrete membrane-enclosed area. Instead, everything is openly accessible within the cell, some of which is free-floating. Prokaryotes belong to two taxonomic domains: the bacteria and the archaea. Archaea were recognized as a domain of life in 1990. These organisms were originally thought to live only in inhospitable conditions such as extremes of temperature, $\mathrm{pH}$, and radiation but have since been found in all types of habitats."

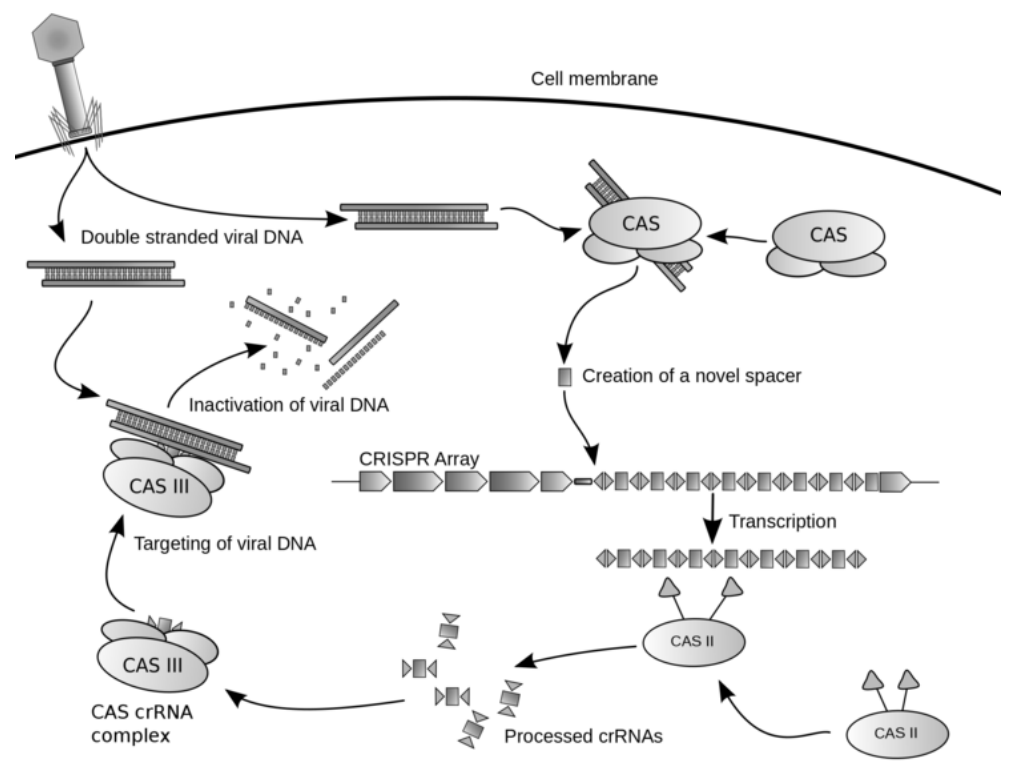

Fig. 5. Diagram of the possible mechanism for CRISPR. http://en.wikipedia.org/wiki/ File:Crispr.png Author: James Atmos 15 September 2009.

\section{CRIPSR: Clustered, Regularly Interspaced Short Palindromic Repeat}

\subsection{CRIPSR (Clustered Regularly Interspaced Short Palindromic Repeats)}

CRISPRs are loci containing multiple short direct repeats that are found in the genomes of approximately $40 \%$ of bacteria and $90 \%$ of archaea. CRISPR functions as a prokaryotic immune system, in that it confers resistance to exogenous genetic elements such as plasmids and phages. The CRISPR system provides a form of acquired immunity. Short segments of foreign DNA, called spacers, are incorporated into the genome between CRISPR repeats, and serve as a 'memory' of past exposures. CRISPR spacers are used to recognize and silence exogenous genetic elements in a way analogous to RNAi in eukaryotic organisms (Fig 5) (2, Grissa et al 2007; Barrangou et al 2007; Marraffini and Sontheimer 2010; Marraddini and Sontheimer 2010). 


\subsection{Self versus non-self discrimination during CRISPS RNA-directed immunity}

All immune systems must distinguish self from non-self to repel invaders without inducing autoimmunity. Clustered, regularly interspaced, short palindromic repeat (CRISPR) loci protect bacteria and archaea from invasion by phage and plasmid DNA through a genetic interference pathway. CRISPR loci are present in $\sim 40 \%$ and $\sim 90 \%$ of sequenced bacterial and archaeal genomes respectively and evolve rapidly, acquiring new spacer sequences to adapt to highly dynamic viral populations. Immunity requires a sequence match between the invasive DNA and the spacers that lie between CRISPR repeats ${ }^{1}$. Each cluster is genetically linked to a subset of the cas (CRISPR-associated) genes that collectively encode $>40$ families of proteins involved in adaptation and interference. CRISPR loci encode small CRISPR RNAs (crRNAs) that contain a full spacer flanked by partial repeat sequences. CrRNA spacers are thought to identify targets by direct Watson-Crick pairing with invasive "protospacer" DNA, but how they avoid targeting the spacer DNA within the encoding CRISPR locus itself is unknown. Here we have defined the mechanism of CRISPR self/nonself discrimination. In Staphylococcus epidermidis, target/crRNA mismatches at specific positions outside of the spacer sequence license foreign DNA for interference, whereas extended pairing between crRNA and CRISPR DNA repeats prevents autoimmunity. Hence, this CRISPR system uses the base-pairing potential of crRNAs not only to specify a target but also to spare the bacterial chromosome from interference. Differential complementarity outside of the spacer sequence is a built-in feature of all CRISPR systems, suggesting that this mechanism is a broadly applicable solution to the self/non-self dilemma that confronts all immune pathways" (Marrafini \& Sontheimer 2010).

\subsection{CRISPR based adaptive and heritable immunity in prokaryotes}

The recently discovered CRISPR (clustered regularly interspaced short palindromic repeat) defense system protects bacteria and archaea against mobile genetic elements. This immunity system has potential to continuously adjust its reach at the genomic level, implying that both gain and loss of information is inheritable. The CRISPR system consists of typical stretches of interspaced repetitive DNA (CRISPRs) and associated cas genes (van der Oost et al. 2009).

\subsection{Hallmark of ingenious antiviral defense mechanisms}

According to Al-Attar et al, many prokaryotes contain the recently discovered defense system against mobile genetic elements. (i) CRISPR-Adaptation, the invader DNA is encountered by the CRISPR/Cas machinery and an invader-derived short DNA fragment is incorporated in the CRISPR array. (ii) CRISPR-Expression, the CRISPR array is transcribed and the transcript is processed by Cas proteins. (iii) CRISPR-Interference, the invaders' nucleic acid is recognized by complementarity to the crRNA and neutralized (2011). An application of the CRISPR/Cas system is the immunization of industry-relevant prokaryotes (or eukaryotes) against mobile-genetic invasion. In addition, the high variability of the CRISPR spacer content can be exploited for phylogenetic and evolutionary studies. Despite impressive progress during the last couple of years, the elucidation of several fundamental details will be a major challenge in future research. (Fig 5) 


\subsection{Structural basis for CRIPSR RNA-guided DNA recognition by cascade and biology seahorse vs. pathogen}

Here is the composition and low-resolution structure of casecade and how it recognizes double-stranded DNA (dsDNA) targets in a sequence-specific manner. Cascade is a $405-\mathrm{kDa}$ complex comprising five functionally essential CRISPR-associated (Cas) proteins (CasA(1)B(2)C(6)D(1)E(1)) and a 61-nucleotide CRISPR RNA (crRNA) with 5'-hydroxyl and 2',3'-cyclic phosphate termini. Cascade recognizes target DNA without consuming ATP, which suggests that continuous invader DNA surveillance takes place without energy investment. The structure of Cascade shows an unusual seahorse shape that undergoes conformational changes when it binds target DNA (Jore et al. 2011). Jore et al. have analyzed the composition and low-resolution structure of the Cascade complex, which lies at the heart of the CRISPR Immune response. The snippets of invader sequence are transcribed and converted into CRISPR RNA (crRNA), which is bound by the Cascade complex. The overall structure of the Cascade complex surprisingly resembled the shape of the seahorse, with the spine and head consisting of a tight curved polymer of six CasC protein subunits, which might binf the crRNA- GR (Riddihough 2011).

\subsection{Structures of the RNA-guided surveillance complex from a bacterial immune system}

According to Wiedenheft et al (2011), bacteria and archaea acquire resistance to viruses and plasmids by integrating short fragments of foreign DNA into clustered regularly interspaced short palindromic repeats (CRISPRs). In Escherichia coli, crRNAs are incorporated into a multisubunit surveillance complex called Cascade (CRISPR-associated complex for antiviral defence), which is required for protection against bacteriophages. They used cryo-electron microscopy to determine the subnanometre structures of Cascade before and after binding to a target sequence. Cascade engages invading nucleic acids through high-affinity base-pairing interactions near the $5^{\prime}$ end of the crRNA. Base pairing extends along the crRNA, resulting in a series of short helical segments that trigger a concerted conformational change. This conformational rearrangement may serve as a signal that recruits a trans acting nuclease (Cas3) for destruction of invading nucleic-acid sequences.

\section{What are eukaryotes?}

A eukaryote is an organism whose cells contain complex structures enclosed within membranes (Figure 4). Eukaryotes may more formally be referred to as the taxon Eukarya or Eukaryota. The defining membrane-bound structure that sets eukaryotic cells apart from prokaryotic cells is the nucleus, or nuclear envelope, within which the genetic material is carried. The presence of a nucleus gives eukaryotes their name, which comes from the Greek عv (eu, "good") and kápvov (karyon, "nut" or "kernel"). Most eukaryotic cells also contain other membrane-bound organelles such as mitochondria, chloroplasts and the Golgi apparatus. All species of large complex organisms are eukaryotes, including animals, plants and fungi, although most species of eukaryote are protist microorganisms. [ Cell division in eukaryotes is different from that in organisms without a nucleus (prokaryotes). It involves separating the duplicated chromosomes, through movements directed by microtubules. There are two types of division processes. In mitosis, one cell divides to produce two genetically identical cells. In meiosis, which is required in sexual reproduction, one diploid 


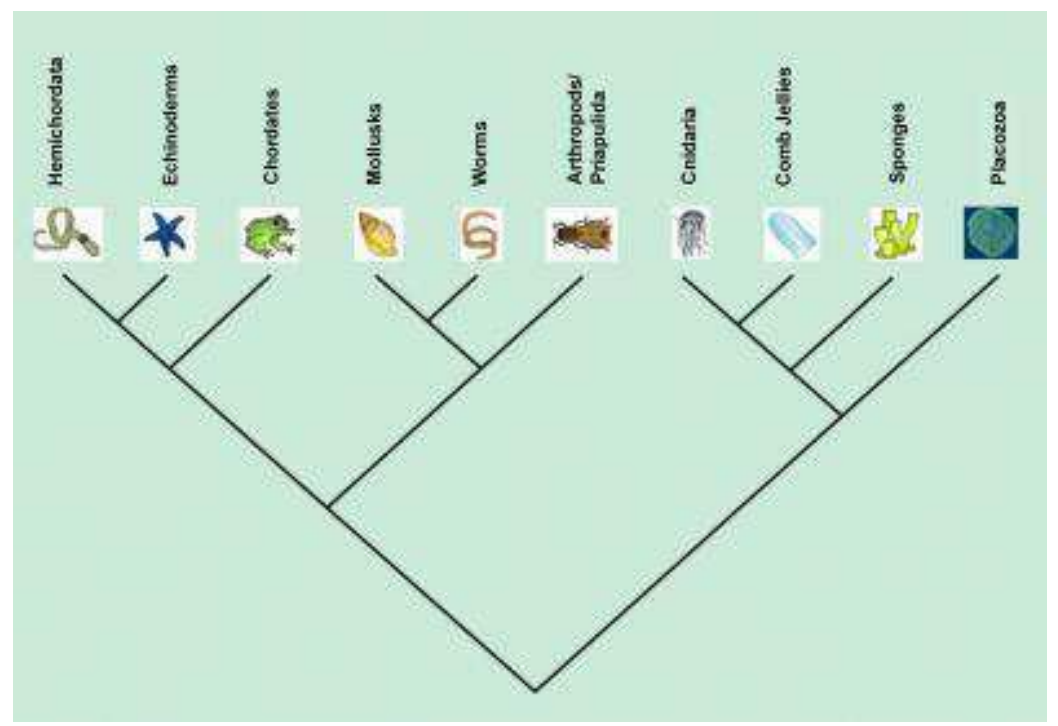

Fig. 6 New metazoan tree of life presented in Schierwater, et al. 2009

http://www.amnh.org/science/papers/metazoan.php Credit: AMNH

cell (having two instances of each chromosome, one from each parent) undergoes recombination of each pair of parental chromosomes, and then two stages of cell division, resulting in four haploid cells (gametes). Each gamete has just one complement of chromosomes, each a unique mix of the corresponding pair of parental chromosomes Eukaryotes appear to be monophyletic, and so make up one of the three domains of life. The two other domains, Bacteria and Archaea, are prokaryotes and have none of the above features. Eukaryotes represent a tiny minority of all living things; even in a human body there are 10 times more microbes than human cells.However, due to their much larger size their collective worldwide biomass is estimated at about equal to that of prokaryotes

\section{Why was the $19^{\text {th }}$ century crucial to the birth of immunology?}

This provides an appropriate background for the analysis of eukaryotes. Darwin and Metchnikoff were laying the foundation for the "big bang" in immunology. It is not crystal clear when that occurred but surely whether directly or indirectly this revelation was the product of a coalescence of all the ferment that the 19th century inspired. In a sense, both were field biologists highly observant and meticulous - willing to take chances on the unexplored and to express their ideas. The inquisitiveness of Darwin and the consequence of Metchnikoff's single prescient observation by the sea both represent a tour de force in the annals of biology (Cooper et al 2002) The origin of species by natural selection underwent metamorphosis in its application to immunology and became the clonal selection theory with its inherent application to and explanation of adaptive immunity (Ribatti 2009] By contrast, Metchnikoff's phagocytosis in starfish larvae became the ancestor of innate immunity, even with the much later advent of T-cells (Silverstein 1989;, Tauber and Chernyak 1991, Besredka 1979). Darwin's well-known epic The Origin of Species was first published in 1859 when he was 50 years old and when Metchnikoff was only 14 years old. 
The crossings and crisscrossing do continue. At 14 years Metchnikoff was already the budding zoologist imbued with an interest in animals, their lives and habitats quite the central thesis of Darwin's work as well that resulted from his now famous expeditions. Metcnikoff's observation split the monolithic field of immunology into two main camps, cellular and humoral giving cause to celebrate both investigations in 2008-2009.

\section{From Darwin and Metchnikoff to Burnet and beyond}

Phagocytosis in unicellular animals represents the most ancient and ubiquitous form of defense against foreign material. Unicellular invertebrates can phagocytose for food and defense. Multicellular invertebrates and vertebrates possess phagocytic cells and have evolved more complex functions attributed to immunodefense cells that specialized into sources of cellular and humoral immune responses. Thus all animals possess: innate, natural, nonspecific (no memory) nonanticipatory, nonclonal, germline (hard wired) host defense functions. In addition, all vertebrates possess: adaptive, induced, specific (memory), anticipatory, clonal, somatic (flexible) immune responses. A similar situation exists with respect to components of the signaling system, immunity and development. With multicellularity, clearly numerous immune response characteristics are not possible in unicellular forms or even those that straddle the divide between unicellularity and multicellularity, beginning with colonial/social protozoans. Still, it is instructive to elucidate a hierarchy of animals based upon immunologic characteristics and how they parallel other physiological traits. Evidence is presented that the most primitive of invertebrates prior to the evolution of multicellular organisms possess varying degrees of complexity at the molecular level of those hallmarks that now characterize the immune system.

According to Cooper (2008) we can now explore easily how potential external threats to life by continuously mutating microbes are first perceived, recognized, and the resulting signals interpreted and presumably survival from infection insured - or the blocking of cancer development an internal threat averted. This chapter will focus primarily on unicellular (Protozoa) and examples of multicellular animals (Sponges, Cnidarians); more complex invertebrates are excluded. Three reasons are presented. First, these two animal groups are situated at the nexus between single cell life and the emergence of multicellularity. Second, the unjustified thinking of immunologists would discredit these two groups with having evolved any semblance of an immune response other than phagocytosis. Third, the information that is included, i.e. the recent discovery of Toll-like receptors (TLRs) justified their inclusion. Finally, TLRs correlate with earlier information that substantiated the immunodefense capabilities as we knew them long ago and credit them today (Tables 1 and 2, Cooper 2008)

\subsection{Emergence of modern immunology may be indebted to invertebrates?}

This discovery of invertebrate phagocytosis dramatically changed the monolithic world of immunology. His careful and detailed observations of white cell motility toward and engulfment of foreign bodies in transparent larvae of starfish and in the water flea Daphnia provoked a major re-evaluation of the nature of immune systems, admittedly restricted to the human good. Before his prescient observations, immune systems were believed to be wholly humoral and there was little emphasis on the role of leukocytes or white cells. Metchnikoff's discovery, however, added cellular immunity to the known armory of 


\begin{tabular}{lccc} 
Genus \& Species & $\begin{array}{c}\text { Assessment of self and } \\
\text { non- self activity }\end{array}$ & Results & $\begin{array}{c}\text { Adhesion protein families } \\
\text { and/or recognition system }\end{array}$ \\
\hline Amoeba & Transplantation & $90 \%$ clones & \\
(Amoeba preteus) & Allogeneic nuclei & $0 \%$ clones & - \\
Amoeba discordes & Xenogeneic nuclei & $0 \%$ clones & \\
\hline
\end{tabular}

Social amoebae

(Dictyostelium

discoideum)

$S$ cells

Slime molds

Choanoflagellates

(Unicellular colonial)
Phagocytosis of bacteria
TIR domain proteins
C-type lectins

Tyrosine kinase signaling components
Ciliata Stentor

Stenor coeruleus

Stentor polymorphus
Lack of Chimera formation

Ejection of

symbiotic Chlorella

Table 1. Recent evidence of signaling systems supported by early evidence of self and nonself recognition in unicellular species.

\begin{tabular}{|c|c|c|c|}
\hline $\begin{array}{l}\text { Genus \& } \\
\text { Species }\end{array}$ & $\begin{array}{l}\text { Assessment of self } \\
\text { and non- self } \\
\text { activity }\end{array}$ & Results & $\begin{array}{l}\text { Adhesion protein families and/or } \\
\text { recognition system }\end{array}$ \\
\hline $\begin{array}{l}\text { Porifera } \\
\text { Sponges } \\
\text { Microciona } \\
\text { prolifera } \\
\text { Cliona celata }\end{array}$ & $\begin{array}{l}\text { Mixing of red and } \\
\text { yellow sponges }\end{array}$ & $\begin{array}{l}\text { Disaggregated sponges to } \\
\text { not reaggregate together }\end{array}$ & - \\
\hline $\begin{array}{l}\text { Demosponges } \\
\text { Suberites } \\
\text { Domuncula }\end{array}$ & $\begin{array}{l}\text { Response to bacterial } \\
\text { lipopeptides }\end{array}$ & - & $\begin{array}{c}\text { TLR, IRAK-41, effector caspase } \\
\text { sequence (SDCA, SL) Homologies in } \\
\text { family-specific domains }\end{array}$ \\
\hline $\begin{array}{l}\text { Cnidaria } \\
\text { Hydrozoa } \\
\text { Hydra } \\
\text { Chlorphydra } \\
\text { Pelmatohydra } \\
\end{array}$ & $\begin{array}{l}\text { Allografts and } \\
\text { xenografts }\end{array}$ & $\begin{array}{l}\text { Incompatible transplant } \\
\text { reactions }\end{array}$ & (2: \\
\hline $\begin{array}{l}\text { Anthozoa } \\
\text { Aborescent } \\
\text { Cnidarians } \\
\end{array}$ & $\begin{array}{l}\text { Autografts } \\
\text { Allografts }\end{array}$ & $\begin{array}{l}\text { Compatible } \\
\text { Incompatible }\end{array}$ & - \\
\hline $\begin{array}{l}\text { Staghorn corals } \\
\text { Acropora }\end{array}$ & $\begin{array}{l}\text { Autografts } \\
\text { Isografts } \\
\text { Allografts }\end{array}$ & $\begin{array}{l}\text { Compatible } \\
\text { Incompatible } \\
\text { Incompatible }\end{array}$ & - \\
\hline $\begin{array}{l}\text { Hydra } \\
\text { magnipapillata }\end{array}$ & - & & - \\
\hline $\begin{array}{l}\text { Nematostella } \\
\text { vectensis }\end{array}$ & - & & - \\
\hline $\begin{array}{l}\text { Coral } \\
\text { (Acropora } \\
\text { millepora) }\end{array}$ & & & $\begin{array}{c}\text { Canonical Toll/TLR Receptor C3, } \\
\text { MAC/PF }\end{array}$ \\
\hline
\end{tabular}

Table 2. Evidence of signaling systems and early evidence of self and non-self recognition in multicellular animals (Porifera and Cnidaria). 
humoral immunodefense mechanisms. Serendipity surely intervened and there was probably the impulse to shout Archimedes' eureka when the interpretation of why cells were moving toward a foreign body was easily visualized. Thus, the foundation for invoking the concept of self non-self recognition was laid (Cooper 1993).

Moreover, there is a much greater willingness to accept that invertebrate model systems have much more to contribute than was thought, even in the early 1960s when modern immunology was beginning to develop. Broadly interpreted, Darwin led us into the field and Metchnikoff into the laboratory at least with respect to comparative immunology (Cooper 1974; Cooper et al 1992). Evolutionary immunology reaped the benefits of Metchnikoff and modern immunology advanced conceptually when the clonal selection theory of Burnet was advanced - in essence a Darwinian corollary (Cooper 1974, Perlovsky 2010). According to Burnet (1962), 'The clonal-selection theory is a generalization about a wide range of biological phenomena but may suffer from the inherent weakness of all biological generalizations. The essence of the clonal-selection theory is that immunity and antibody production are functions of clones of mesenchymal cells. Each clone is characterized by the ability of its component cells to react immunologically with a very small number of antigenic determinants (Ribatti 2009).

Contact with the right antigenic configuration acts as a trigger to action and it is the essence of a clonal theory that such stimulation plays a major part in determining the observed changes in type and numbers of the mesenchymal cells of the body. The trigger of immunological contact is believed to provoke actions which, depending on many associated factors, may take one or other several forms. The cells may be killed or damaged, with release of cell-damaging or stimulating products; they may be stimulated to proliferate, with or without change of morphological type; or they may be converted to the plasma-cell form, with its capacity for active synthesis and liberation of antibody. Which particular reaction ensures will depend essentially on the physiological state of the cell and the nature of the internal environment to which it is exposed after stimulation.' (Burnet 1970) .

\subsection{Origins of immune system components}

\subsubsection{Unicellular colonial protozoans}

One approach to origin of animals is to determine which developmental proteins predated them and were subsequently co-opted for their development. Another strategy involves comparative genomics that can identify the minimal set of intact genes from the beginning of animal evolution that reveals those shared by all animals and their nearest relatives. Resolving the mystery of origins, these workers have sampled gene diversity expressed by choanoflagellates, unicellular and colonial protozoa that are closely related to metazoa, crucial for providing a possible clue into early animal evolution. Results revealed that choanoflagellates express representatives of a surprising number of cell-signaling and adhesion protein families not previously isolated from nonmetazoans; these include cadherins, C-type lectins, several tyrosine kinases and tyrosine kinase signaling pathway components. Choanoflagellates have a complex and dynamic tyrosine phosphoprotein profile, and tyrosine kinase inhibitors selectively affect cell proliferation. The expression in choanoflagellates of proteins involved in cell interaction in metazoa demonstrates that these proteins evolved before the origin of animals and were later co-opted for development. A similar situation exists with respect to components of the signaling system with respect to immunity and development. (Fig 6) 


\subsubsection{Emergence of multicellularity: social amoeba}

Social amoebae feed on bacteria in the soil but aggregate when starved to form a migrating slug. Chen et al (2007) discovered an unknown cell type in social amoeba that is apparently involved in detoxification and immune-like functions; they call it the sentinel (S) cells. $S$ cells engulf bacteria and sequester toxins while circulating within the slug, eventually being sloughed off. A Toll/interleukin-1 receptor (TIR) domain protein, TirA, is also required for certain $\mathrm{S}$ cell functions and for vegetative amoebae to feed on live bacteria. This apparent innate immune function in social amoebae, and the use of TirA for bacterial feeding, suggests an ancient cellular foraging mechanism that may have been adapted to defense functions well before the diversification of animals. Multicellularity likely increased the selective pressure on an organism's ability to avoid exploitation by pathogens. The role of TirA in Dictyostelium's response to bacteria provides $t$ he first glimpse of an immune-related signaling system in amoeba and suggests that the use of TIR domain based signaling for defense represents an ancient function present in the progenitor of all crown group eukaryotes. If true, it would suggest that this system of pathogen recognition was advantageous to organisms before the evolution of multicellularity.

\subsubsection{Sponges}

Sponges (phylum Porifera) are filter feeders, therefore they are extremely exposed to microorganisms that represent a potential threat. Examining sponges, therefore moving to a higher taxonomic level, Wiens et al. 2007 have identified, cloned and deduced the protein sequence from 3 major elements of the poriferan innate response (to bacterial lipopeptides according to these definitions): the TLR, the interleukin-1 (IL-1) receptor-associated kinase4-like protein (IRAK-4l), and a novel effector caspase from the demosponge Suberites domuncula. Each molecule shares significant sequence similarity with its homologues in higher metazoa. There are sequence homologies within the family-specific domains Toll/IL1 receptor/resistance (TLR family), Ser/Thr/Tyr kinase domain (IRAK family), and CASc (caspase family).

\subsubsection{Hydra and corals}

Recently, whole genome sequences became available for two cnidarians, Hydra magnipapillata and Nematostella vectensis, and large expressed sequence tag datasets are available for them and for the coral Acropora millepora. (Powell 2007) A canonical Toll/TLR pathway in representatives of cnidarians of the class Anthozoa was observed. Neither a classic Toll/TLR receptor nor a conventional nuclear factor- $\beta$ was identified in Hydra - an anthozoan. The detection of complement C3 and several membrane attack complex/perforin domain (MAC/PF) proteins suggests that a prototypic complement effector pathway may exist in anthozoans, but not in hydrozoans. Together with information for several other gene families, they suggest that Hydra may have undergone substantial secondary gene loss during evolution. Such patterns of gene distribution may underscore possible significance of gene loss during animal evolution but indicate ancient origins for components of vertebrate innate immune systems. (Miller et al 2007) 


\subsection{Toll-like receptors: innate sensing}

Chen et al. (2007) review the earliest work in relation to current views. Phagocytes that engulf bacteria form part of the innate immune system of animals in the defense against pathogens. According to Beutler et al (2003), in humans innate immune sensing usually proceeds through the activation of 10TLRs, and these in turn lead to the production of cytokine mediators that create the inflammatory milieu and collaborate in developing an adaptive immune response. Each TLR senses a different molecular component of microbes that have invaded the host.

TLR4 senses bacterial endotoxins (lipopolysaccharide), TLR9 unmethylated DNA, and TLR3 double-stranded RNA. Each receptor has a conserved signaling element called the TIR (Toll/IL-1 receptor/resistance) motif that transduces a signal through five cytoplasmic adapter proteins, each of which has a homologous motif. (Hoffman 2004). With respect to TLRs, the integration of signals that receptors emit is a crucial mechanism that requires resolution. (Ferrandon et al 2004) By creating random germline mutations in mice and screening for individuals with differences in signaling potential, the complex biochemical circuitry of the innate immune response can be unraveled. Up to now, more than 35,000 germline mutants have been produced, and approximately 20,000 have been screened to predict innate immunodeficiency states (Medzhitov 2000).

\subsubsection{Toll-like receptors in invertebrates and vertebrates: application to human diseases seems real}

\subsubsection{Annelids}

Toll-like receptors (TLRs) are an important component of the innate immunity system and are found throughout the animal kingdom, but have not yet been fully analyzed in annelids. We searched shotgun reads of the genomes of the leech Helobdella and polychaete Capitella for TLR homologs. We found $10^{5}$ TLR homologs in Capitella and 16 in Helobdella (Davidson et al 2011). The deduced phylogeny of these sequences, together with TLRs from other animal phyla, reveals three major clades (A clade is a group consisting of a species [extinct or extant] and all its descendants.). One clade consists of a mixture of both vertebrates and invertebrates, including sequences from Capitella and Helobdella, while the other two clades contain only invertebrate TLRs. Now these represent a beginning in need of further analysis especially with respect to p53 (TLR) and existence of cancer. This is needed since earthworm immune responses are well defined (Cooper et al 2002). Moreover early attempts to induce cancer were not successful (Cooper 1969); new trials are proposed combined with analyses of p53.

\subsubsection{Molluscs}

Toll-like receptor (TLR) signaling pathway is an important and evolutionarily conserved innate immune pathway. Phylogenetic lineage of this pathway in the Lophotrochozoans is still less understood. (The Lophotrochozoa comprise one of the major groups herein annelids and molluscs within the animal kingdom, In turn, the Lophotrochozoa belongs to a larger group within the Animalia called the Bilateria, because they are bilaterally symmetrical with a left and a right side to their bodies) is still less understood. Zhang and Zhang (2011) have cloned a novel TLR, a key component of TLR pathway, from the oyster, 
and named it CgToll-1. Real-time reverse transcription polymerase chain reaction analysis revealed that the highest CgToll-1 expression level was in hemolymph, and this pattern increased dramatically in the presence of bacteria Vibrio anguillarum. TLR pathway core genes of molluscs were searched and compared with model invertebrates revealing that their genes were closer to the fruit fly Drosophila melanogaster than to the purple sea urchin Strongylocentrotus purpuratus, while three upstream genes (MyD88, IRAK, TRAF6) were not closer. They also found that these two downstream genes were significantly more conserved than the three upstream genes based on amino acid sequence alignment. Results suggests that CgToll-1 is a constitutive and inducible protein that could play a role in immune responses against bacterial infection.

\subsubsection{Ascidians}

It is appropriate to present information on the ascidian since they are the nearest invertebrate relative of vertebrates (see Figs 1 and 2). According to Sasake et al (2009), key transmembrane proteins in the innate immune system, Toll-like receptors (TLRs), probably occur in the genome of non-mammalian organisms including invertebrates. However, authentic invertebrate TLRs have only been recently investigated structurally and functionally. Inflammatory cytokine production of the ascidian Ciona intestinalis, designated as Ci-TLR1 and Ci-TLR2 have been analyzed. The amino acid sequence of Ci-TLR1 and CiTLR2 possessed unique structural organization with moderate sequence similarity to functionally characterized vertebrate TLRs. ci-tlr1 and $c i-t l r 2$ genes were mostly expressed in the stomach, and in hemocytes. Both Ci-TLR1 and Ci-TLR2 stimulate NF-KB induction in response to multiple pathogenic ligands such as double-stranded RNA, and bacterial cell wall components that are differentially recognized by respective vertebrate TLRs.This revealed that $\mathrm{Ci}$-TLRs recognize broader pathogen-associated molecular patterns than vertebrate TLRs. The Ci-TLR-stimulating pathogenic ligands also induced expression of CiTNFa in intestine and stomach where Ci-TLRs are expressed. These results provide evidence that TLR-triggered innate immune systems are essentially conserved in ascidians, and that Ci-TLRs possess "hybrid" biological and immunological functions, compared with vertebrate TLRs. This is significant since ascidians are the nearest ancestor to vertebrates.

\subsubsection{Birds}

The Toll-Like receptor (TLR) pathway plays is crucial in innate immunity and is maintained with amazing consistency in all vertebrates. Considering this background of substantial conservation, any subtle differences in this pathway's composition may have important implications for species-specific defense against key pathogens. Cormican et al (2009) used a homology-based comparative method to characterize the TLR pathway the employed the recently sequenced chicken and zebra finch genomes from two distantly related bird species. Primary features of the TLR pathway are conserved in birds and mammals, despite some clear differences. TLR receptors show a pattern of gene duplication and gene loss in both birds when compared to mammals. They found avian specific duplication of both TLR1 and TLR2 and a duplication of the TLR7 gene in zebra finch. Both positive selection and gene conversion may shape evolution of avian specific TLR2 genes. Results contribute to characterization of differing immune responses that have evolved in individual vertebrates in response to their microbiological environment. Birds have been considered since they usually receive less coverage than mammals. Moreover without them we would have been slow to recognize the $\mathrm{T}$ and $\mathrm{B}$ system. 


\subsubsection{Disease and TLR}

Now we consider an example of another disease related to the immune system, having presented cancer as the first example. It is well to remember however that cancer can now be considered to occur in invertebrates. This is a major resolution after many years of speculation concerning its absence. Ngoi et al (2001) have raised awareness of the incidence of allergic disorders and increased autoimmune diseases especially in developed nations. The hygiene hypothesis suggests that as a living environment becomes more sanitized, children are not exposed to microbial and parasitic stimulations that were once commonly acquired since early in life; this caused a lack of immune sensitization tending towards $\mathrm{T}$ helper 2 (Th2) dominance. Thus we can conclude that the immune system perhaps like the nervous system requires early learning experiences in order to respond to antigen stimulation. This view may explain allergic disorders, which mostly result from hyper Th2 responses, but inadequate in explaining Th1 or Th17-based autoimmunity increases.

With respect to signaling, recent advances in experimental mouse models revealed that stimulation of Toll-like receptors (TLRs) by pathogen-associated molecular patterns could reduce symptoms of allergic airway disease and prevent the onset of autoimmunity. For one explanation, the underlying mechanism for protective effects of TLR ligands is currently under investigation and there are indications that IL-10-producing B cells, regulatory T cells, and innate immune cells play an important role during this process. That early exposure to microbial byproducts probably contributes to modulation of immunological disorders may once again modify our interpretation of the hygiene hypothesis.

\section{Cancer development in invertebrates may be linked to the presence of tumor suppressor genes independent of the innate immune system?}

According to immunosurveillance, the adaptive immune system evolved to protect multicellular organisms against harmful invaders (bacteria, viruses, fungi-any disturbance of non-self material not acceptable to self) earlier thought of exclusively as threats from the external environment; however, internal threats may now include cancer cells growing out of control. These characteristics were restricted to vertebrates with adaptive immune responses. And invertebrates were not considered since it was assumed based mostly upon field observations that invertebrates with an innate system did not develop cancer. Some even assumed that the short life span of countless invertebrates precluded the development of any visible tumors. Thus the generalization: innate immunity either protects against cancer or it is so fast acting and efficient, more than the seemingly more complex vertebrate system that they do not develop cancer. Now it is becoming increasingly clear that invertebrates may also develop cancer. It seems safe to conclude that the influence may rest partially on p53 or its family members: p63, 73.

p53 (also known as protein $\mathbf{5 3}$ or tumor protein $\mathbf{5 3}$ ), is a tumor suppressor protein that in humans is encoded by the TP53 gene. p53 is crucial in multicellular organisms, where it regulates the cell cycle and, thus, functions as a tumor suppressor that is involved in preventing cancer. As such, p53 has been described as "the guardian of the genome", the "guardian angel gene", and the "master watchman", referring to its role in conserving stability by preventing genome mutation. $p 53$ continues to be one of the most intensively studied genes in cancer biology. p53 was initially identified $>20$ years ago as a binding partner for the SV40 T oncoprotein. Further studies revealed that p53 is a tumor suppressor gene that is mutated or 
inactivated in $>50 \%$ of human cancers. Furthermore, germ-line p53 mutations cause hereditary cancer in both mice and humans. Molecular and biochemical assays revealed that the p53 protein is a sequence-specific DNA-binding transcription factor. p53 plays a central role in cellular responses to aberrant growth signals and certain cytotoxic stresses, such as DNA damage, by enhancing the transcription of genes that regulate a variety of cellular processes including cell cycle progression, apoptosis, genetic stability, and angiogenesis.

According to Walker et. al., (2011) the human p53 tumor suppressor protein is inactivated in many cancers; it is also crucial in apoptotic responses to cellular stress. p53 protein and the two other members (p63, p73) are encoded by distinct genes, whose functions have been extensively documented for humans and other vertebrates. The structure and relative expression levels for members of the p53 superfamily have also been reported for most invertebrates. Using classical model organisms (nematodes, anemones and flies) reveal that the gene family originally evolved to mediate apoptosis of damaged germ cells or to protect germ cells from genotoxic stress. Analyses of p53 signaling pathways in marine bivalve cancer and stress biology studies suggest that p53 and p63/73-like proteins in soft shell clams (Mya arenaria), blue mussels (Mytilus edulis) and Northern European squid (Loligo forbesi) have identical core sequences. Still we know little about the molecular biology of marine invertebrates to address molecular mechanisms that characterize particular diseases. Understanding the molecular basis of naturally occurring diseases in marine bivalves is a virtually unexplored aspect of toxicoproteomics and genomics and related drug discovery. Marine bivalves could provide the most relevant and best understood models for experimental analyses by biomedical and marine environmental researchers.

The Drosophila tumor-suppressor gene lethal malignant brain tumor [1(3)mbt] (Bonasio et al., 2010) was first identified as a temperature-sensitive mutation that caused malignant growth in the larval brain (Gateff, et al 1993). These long awaited observations provided ample background for further analysis after discovery of tumor suppressors. According to Janic et al (2010), model organisms such as the fruit fly Drosophila melanogaster can help to elucidate the molecular basis of complex diseases such as cancer. Mutations in the Drosophila gene lethal malignant brain tumor (mbt) cause malignant growth in the larval brain. It has been shown that 1(3)mbt tumors exhibited a soma-to-germline transformation through the ectopic expression of genes normally required for germline stemness, fitness, or longevity. Orthologs of these genes are also known to be expressed in human somatic tumors. Moreover, inactivation of any of the germline genes nanos, vasa, piwi, or aubergine suppressed 1(3)mbt malignant growth. There was a consensus: results demonstrated that germline traits are necessary for tumor growth in this Drosophila model. Moreover inactivation of germline genes might have tumor-suppressing effects in other species which could inspire further investigations especially in those other invertebrates such as earthworms in which innate immune systems are well defined (Cooper et al 2002).

Receiving support for the work of Janic et al, Wu and Ruykun (2010) suggest that cancer cells and germ cells share several characteristics. For instance, both have the ability to rapidly proliferate, typically do not lose the ability to divide as they age (lack senescence), and exist in undifferentiated states. Although some genes involved in cancer may initiate disease simply by activating cell division, others may promote tumors by activating early developmental pathways associated with programming for multipotency (the ability to differentiate into different cell types). Janic et al. (2010) have revealed that in fruit flies several genes typically involved in early programming of germline cells also play a role in 
the formation of malignant brain tumor. Moreover by inactivating these germ cell genessome of which have related genes abnormally expressed in certain human cancers-can suppress tumor growth, suggesting new and future avenues for developing therapy.

If the expression of germline characteristics is common in tumors, for instance, it should be observable in gene expression analyses of human tumors. Indeed, the Piwil2 protein, a human Piwi family member, is widely expressed in several solid tumors. It should be feasible to examine more carefully the expression of germ cell genes, including vasa and nanos, in human tumors by microarray or deep RNA sequencing. The retinoblastoma tumor that stimulated analysis of this pathway provides a suitable candidate for studying germline gene activity in tumorigenesis. In addition, mutations in the human homologs of L(3)MBT, $\mathrm{Rb}$, and its chromatin cofactors may be common in cancer genomes as they are sequenced. A query of the human homologs of these genes at the Cosmic web site (www.sanger.ac.uk/genetics/CGP/cosmic), for instance, revealed somatic mutations in $\mathrm{L}(3) \mathrm{MBT}, \mathrm{Rb}$, and CHD3 (an Mi2 homolog) in a small fraction of tumors. Because there are so many mutations in these tumors, however, a more sophisticated statistical analysis is needed. The up-regulation of germline pathways in the l(3)mbt brain tumors and the required role for some of these genes in tumor growth also suggest new possibilities for tumor therapy. These genes are also conserved in mammals and could be potential targets for drugs that treat tumors similar to those analyzed by Janic et al. (2010)

Let us focus on new information that correlates with an animal model and cancer development. According to Read, (2011) glioblastomas (GBM), the most common primary brain tumors, infiltrate the brain, grow rapidly, and are refractory to current therapies. To analyze the genetic and cellular origins of this disease, a novel Drosophila GBM model is now available; Glial progenitor cells give rise to proliferative and invasive neoplastic cells that create transplantable tumors in response to constitutive co-activation of the EGFR-Ras and PI3K pathways. Since there is relevance of Drosophila to human cancer, neurological disease, and neurodevelopment, this fly model represents a neurological disease model wherein malignant cells are created by mutations in genetic pathways that may act in a homologous human disease. By using lineage analysis and cell-type specific markers, neoplastic glial cells presumably originated from committed glial progenitor cells, and not from multipotent neuroblasts. Genetic analyses demonstrated that EGFR-Ras and PI3K induce fly glial neoplasia through activation of a combinatorial genetic network that is partially comprised of other genetic pathways that are also mutated in human glioblastomas. Future research should focus on extensive genetic screens utilizing this model that could reveal new insights into origins and treatments of human glioblastoma.

\section{Perspectives on parasitsm, cancer and immunity}

For the past half-century, the dominant paradigm of oncogenesis has been mutational changes that disregulate cellular control of proliferation. The growing recognition of the molecular mechanisms of pathogen-induced oncogenesis and the difficulty of generating oncogenic mutations without first having large populations of dysregulated cells, however, suggests that pathogens, particularly viruses, are major initiators of oncogenesis for many if not most cancers, and that the traditional mutation-driven process becomes the dominant process after this initiation. Molecular phylogenies of individual cancers should facilitate testing of this idea and the identification of causal pathogens (Ewald 2009). 


\section{Pathogen survival in the external enviornment and the evolution of virulence}

Recent studies have provided evolutionary explanations for much of the variation in mortality among human infectious diseases. Walther and Ewald's findings bear on several areas of active research and public health policy: (1) many pathogens used in the biological control of insects are potential sit-and-wait pathogens as they combine three attributes that are advantageous for pest control: high virulence, long durability after application, and host specificity; (2) emerging pathogens such as the 'hospital superbug' methicillin-resistant Staphylococcus aureus (MRSA) and potential bio-weapons pathogens such as smallpox virus and anthrax that are particularly dangerous can be discerned by quantifying their durability; (3) hospital settings and the AIDS pandemic may provide footholds for emerging sit-and-wait pathogens; and (4) studies on food-borne and insect pathogens point to future research considering the potential evolutionary trade-offs and genetic linkages between virulence and durability (2004).

All evidence indicates that clonal selection is purely a vertebrate strategy and therefore irrelevant to invertebrates. Some views may insist that anthropocentric mammalian immunologists utilized a tool to propel: the universal innate immune system of ubiquitous and plentiful invertebrates as an essential system for vertebrates. Innate immunity should help if there is a failure of the adaptive immune system. Still to be answered are questions concerning immunologic surveillance that includes clonal selection. We can then ask does immunologic surveillance play a role in the survival of invertebrates that most universally seem to not develop cancer at least of the vertebrate type. Perhaps invertebrates with their efficient innate immune system evolved certain "canceling devices" that maintain survival with short life spans, thus precluding their demise by metastasis.

\section{Ancient neurons regulate immunity: innate innervation}

According to Tracy (2011), the most evolutionarily ancient type of immunity, called "innate," exists in all living multicellular species. When exposed to pathogens or cellular damage, cells of an organism's innate immune system activate responses that coordinate defense against the insult, and enhance the repair of tissue injury. There is a modern-day cost associated with these processes, however, because innate mechanisms can damage normal tissue and organs, potentially killing the host. Human life is a balance between dual threats of insufficient innate immune responses - which would allow pathogens to prevail-and overabundant innate immune responses-which would kill or impair directly. What has been the key to maintaining this balance throughout years of mammalian evolution?

In this study, the nervous system controlled the activity of a noncanonical UPR pathway required for innate immunity in Caenorhabditis elegans. OCTR-1, a putative octopamine G protein-coupled catecholamine receptor (GPCR, G protein-coupled receptor), functioned in sensory neurons designated ASH and ASI to actively suppress innate immune responses by down-regulating the expression of noncanonical UPR genespqn/abu in nonneuronal tissues. Findings suggest a molecular mechanism by which the nervous system may sense inflammatory responses and respond by controlling stress-response pathways at the organismal level. 


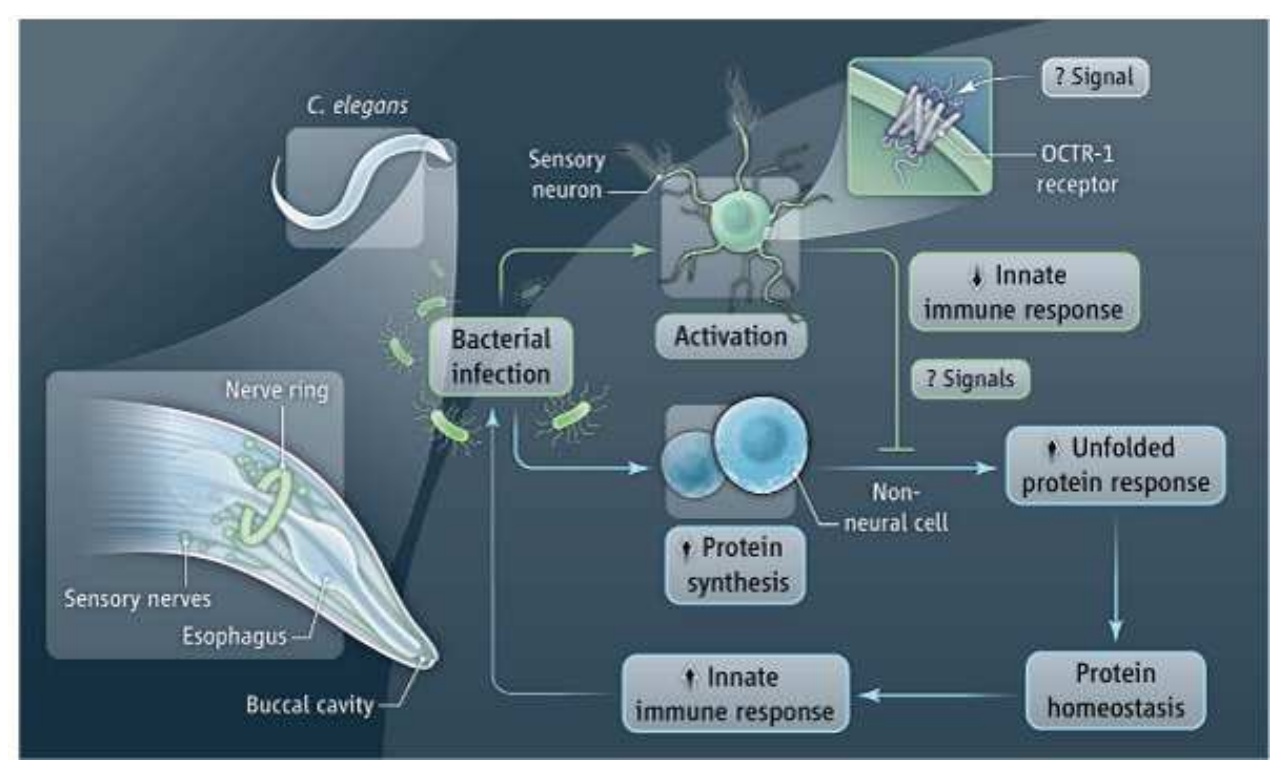

Fig. 7. Infection of $C$. elegans with a pathogen stimulates the innate immune response and activates the synthesis of new proteins, potentially causing the accumulation of unfolded proteins in host cells. (Tracey, 2011) The OCTR-1 receptor in the sensory neurons is required for this effect (figure 5). http:/ / designmatrix.wordpress.com/ 2009/02/03/front-loadingneurons-more-supporting-evidence.

\section{Perspectives}

Clearly engaging TLRs activates various inflammatory and innate immune responses throughout the animal and plant kingdoms. This is associated with the innate immune system and must depend therefore on the presence, at least for now, of a multicellular system. Thus we would not expect as far as we have current information that prokaryotes would have evolved such a system. At the moment it is even with great difficulty to imagine such. Of course the thrust of this chapter refutes common dogma for it reports the existence of adaptive immunity in prokaryotes! But this impasse has been due to restricted definitions and these in turn due to restricted information based primarily on the dearth of molecular data. Ongoing efforts in many laboratories have led to the identification of TLR-specific signaling components and cellular responses within every major group -setting aside a wealth of new taxonomic data based on TLR. Perhaps this is a turning point in that the existence of TLR is so very basic, it seems inconceivable that investigations will reveal significant departures from what we know already. TLRs function in combination with additional pattern-recognition receptors and co-receptors to add further diversity to their role in vivo. How hosts integrate information that is signaled through TLRs and any coreceptors will ultimately control progression of the immune response to pathogens. Understanding this process will surely lead to newer fields that seek to develop novel therapeutics and immune boosting products. 
Toll-like receptors (TLRs) are pattern-recognition receptors related to the Drosophila Toll protein (Adams 2009). TLR activation alerts the immune system to microbial products and initiates innate and adaptive immune responses. The naturally powerful immunostimulatory property of TLR agonists can be exploited for active immunotherapy against cancer. Antitumor activity has been demonstrated in several cancers, and TLR agonists are now undergoing extensive clinical investigation. Once there is more information, field and will focus on opportunities for clinical development of TLR agonists as single agent immunomodulators, vaccine adjuvants and in combination with conventional cancer therapies.

\section{Conclusion}

Perlovsky (2010) poses a pervasive and difficult question that challenges the utility of the immune system in relation to survival "Why deadly diseases exist from an evolutionary viewpoint? Some diseases, e.g. Influenza are clear; the disease agents are multiplying inside the host. But why cancer exists? According to surveillance, cancer poses an internal threat, in which cells no longer become recognizable as self (self/not self model) and therefore become cancerous and out of control. In this instance, the driving force for evolution of the immune system could be to effectively keep potentially cancerous cells in check, not allowing their uncontrolled metastases.

This review has covered enormous ground with respect to the immune system beginning with the view that microbes possess a form of adaptive immunity for protection against invading viruses. This is an interesting view and renders the immune system more encompassing than previous conceptions. By including the prokaryotes and eukaryotes and analyzing their responses to survival the immune system embraces a newer and broader scope than before when it was restricted to the higher eukaryotes. Gradually we have come to accept the innate immune system that characterizes the armamentarium of plants, invertebrates and vertebrates, it is only the vertebrates which at the moment whose immune system is associated with the appearance of cancer. Now two other points are worthy to raise and may bring us to another level of understanding of the immune system and in this light, I present at least two views concerning living systems in general and the immune system in particular.

In a recent review, the existence of artificial immune systems (AIS ) has been presented (Cooper, 2010). Although not clearly defined, it is assumed that the field of AIS concerns an analysis of and development of computationally interesting abstractions of the immune system. Relevant to the current review there is the suggestion that to understand AIS could be inspired from organisms that possess only innate immune system. Moreover there is the suggestion that AISs should employ systemic models of the immune system in order to construct their overall design. For precision AIS should include plant and invertebrate immune systems.

Now we approach a new view presented recently by Bruce Alberts, Editor in Chief of Science (2011). He suggests recently: "A Grand Challenge in Biology" posing several questions and solutions aimed at advancing the field of synthetic biology. He emphasizes the need for basic research aimed at attaining a deep understanding of the chemistry of life. He further urges that a complete catalog of the tens of thousands of different 
molecules present in a human or mouse cell, along with a map of their myriad mutual interactions, is likely to be obtained with the wide variety of different techniques that are now available. Now, we are even closer to the present chapter and certainly suggestive of relevance to prokaryote immune systems. Albert's suggests: "Because all living things on earth are related through evolution, one can bootstrap one's way to understanding human cells by discovering how simpler cells and organisms work". A detailed study of Mycoplasma genitalium, a tiny bacterium that causes human disease, suggests that it can grow and divide with a minimal set of only about 430 genes. This suggests that we may be largely ignorant of some critical functions of proteins, such as their roles in the exquisite spatial organization of the molecules inside cells. (Alberts 2011). Of particular relevance is an article in the news section devoted to virus immunity by George Church, written by Bohannon, J. (2011)

\section{Acknowledgements}

Acknowledgement: I acknowledge with pleasure the superb assistance of Jesus Heredia and Kyle Hirabayashi.

\section{References}

Adams S. (2009). Toll-like receptor agonists in cancer therapy. Immunotherapy. 2009, 6, pp.(949-64), 101485158

Janic A, Mendizabal L, Llamazares S, Rossell D \& Gonzalez C. (2010). Ectopic expression of germline genes drives malignant brain tumor growth in Drosophila. Science. 2010 Dec, pp.(1824-1827)

Al-Attar S., Westra E.R., van der Oost J., Brouns S.J. (2011) Clustered regularly interspaced short palindromic repeats (CRISPRs) the hallmark of an ingenious antiviral defense mechanism in prokaryotes. Biol Chem, 392, 4, pp. (277-89), 9700112

Alberts B. (2011). A grand challenge in biology. Science 333, 2011, pp.(120), 0404511

Barrangou R, Fremaux C, Deveau H, Richards M, Boyaval P, Moineau S, Romero DA \& Horvath P. (2007). CRISPR provides acquired resistance against viruses in prokaryotes. Science. 2007 Mar. pp.(1709-1712)

Besredka A. (1979). The story of an idea. Rivenson A, Oestreicher R, Trans.]. Bend, OR: Maverick; 1979

Beutler B, Hoebe K, Du X, Ulevitch RJ: How we detect microbes and respond to them: the Toll-like receptors and their transducers. J Leukoc Biol, 74, 4 2003, October, 74 pp.(479-485), 0741-5400

Bonasio R, Lecona E, \& Reinberg D. (2010). MBT domain proteins in development and disease.Semin Cell Dev Biol. 2010, 2, pp(221-30), 9607332

Bohannon, J. (2011). The Life Hacker. Science 333, pp.(1236-1237), 0404511 [

Burnett FM. (1959). The clonal selection theory of acquired immunity. Nasville, Vanderbilt University Press; 1959

Burnet, M. Role of the thymus and related organs in immunity. Br Med J. 1962 Sep 29;2(5308):807-11.

Burnet FM. (1970). Immunological surveillance. Oxford: Pergamon; 1970.

Chen G, Zhuchenko O, Kuspa A. (2007). Immune-like phagocyte activity in the social amoeba. Science. 2007, 317. pp.(678-81), 0404511 
Cooper, E. L. 1969. Neoplasia and transplantation immunity in annelids. J. Nat. Cancer Inst. 31: 655-669.

Cooper EL, Rinkevich B, Uhlenbruck G, Valembois P. (1992). Invertebrate immunity: Another viewpoint. Scand J Immunol 1992;35, pp.(247-66), 0323767

Cooper EL. In: Cooper EL, Nisbet-Brown E, editors. Developmental immunology. New York: Oxford University Press; 1993. pp. (3-30),

Cooper EL, Kauschke E, Cossarizza A. (2002). Digging for innate immunity since Darwin and Metchnikoff. (2002). Bioessays. 2002 Apr;24(4) pp.(319-333) 8510851

Cooper EL, Kvell K, Engelmann P, Nemeth. Still waiting for the toll? P.Immunol Lett. 2006, Apr 15, 104, 1 pp,(18-28) , 7910006

Cooper, EL. From Darwin and Metchnikoff to Burnet and beyond. (2008). Contrib Microbiol. 2008, 15. pp(1-11), 1662-291X, 9815689

Cooper, E.L. Evolution of immune systems from self/not self to danger to artificial immune systems (AIS). Phys Life Rev. 2010 Mar;7(1):55-78 2009, 101229718

Cooper, E.L. Self/not self, innate immunity, danger, cancer potential. Phys Life Rev. 2010. Feb, pp.(85-86) 101229718

Cooper, EL. (2010). Evolution of immune systems from self/not self to danger to artificial immune systems (AIS). Phys Life Rev. 2010 Mar, pp.(55-78), 101229718

Cooper, EL. (2010). Self/not self, innate immunity, danger, cancer potential. Phys Life Rev. 2010 Feb 1. pp.(55-78), 101229718

Cossarizza, A. (2010). Know thyself and recognize dangers: An evolutionistic view. Phys Life Rev. 2010 Mar. pp.(81-82), 1873-1457, 101229718

Davidson CR, Best NM, Francis JW, Cooper EL, \& Wood TC. (2011). Toll-like receptor genes (TLRs) from Capitella capitata and Helobdella robusta (Annelida). Jourl of Biol Chem. 2011, 284, pp.(608-612), 7708205

Du Pasquier L, \& Litman GW. (2000) Origin and evolution of he vertebrate immune system, current topics in microbiology and immunology.2000, Heidelberg, Germany, Springer, 3540664149

Engelmann P. and Nemeth. (2010). Immune evolution and autoimmunity. Phys life Rev, 2010. 7, 1, pp.(79-80), 101229718

Ewald PW. (2009). An evolutionary perspective on parasitism as a cause of cancer. Adv Parasitol. 2009, 68, pp.(21-43), 0370435

Ferrandon D, Imler JL, Hoffmann JA. Sensing infection in Drosophila: Toll and beyond. Semi. Immunol. 2004, 16,. pp.(43-53), 9009458

Franc NC, Dimarcq J-L, Lagueux M, Hoffmann J, \& Ezekowitz RAB. (1996). Croquemort, a novel Drosophila hemocyte/macrophage receptor that recognizes apoptotic cells. Immunity. 1996, 4.5, pp.(431-43), 9432918

Gateff et al 1993. A temperature-sensitive brain tumor suppressor mutation of Drosophila melanogaster: developmental studies and molecular localization of the gene. Mech Dev. 1993 Apr, pp.(15-31),

Grissa I, Bouchon P, Pourcel C \& Vergnaud G. (2008). On-line resources for bacterial microevolution studies using MLVA or CRISPR typing. Biochimi. 2008, April, pp.(660668)

Hildemann WH, Raison RL, Cheung G, Hull CJ, Akaka L, \& Okamoto J.(1977). Immunological specificity and memory in a scleractinian coral. Nature. 1977, 270, pp.(219-2230), 0410462 
Hoffmann JA. (2004). Primitive Immune Systems., Immunological Reviews 2004, 198, pp.(5-9), 1600-065X

Jore, M.M., Lundgren, M., van Duijn, E., Bultema, J.B., Westra, E.R., Waghmare, S.P., Wiedenheft, B., Pul, U., Wurm, R., Wagner, R., Beijer, M.R., Barendregt, A., Zhou, K., Snijders, A.P., Dickman, M.J., Doudna, J.A., Boekema, E.J., Heck, A.J., van der Oost, J., Brouns, S.J. (2011) Structural basis for CRISPR RNA-guided DNA recognition by Cascade. Nat Struct Mol Biol. 2011 May, 18, 5, pp.(529-36), 101186374

Kvell K, Cooper EL, Engelmann P, Bovari J, Nemeth. (2007). Blurring borders: innate immunity with adaptive features. (2007). P.Clin Dev Immunol. 2007, pp.(1-10), 101183692

Luke A.J. O'Neill. (2011) Innate Immunity in Plants Goes to the PUB. (2011). Science 332, 2011, June, pp.(1386-1387), 0404511

Marraffini LA \& Sontheimer EJ. (2010). CRISPR interference: RNA-directed adaptive immunity in bacteria and archaea. Nat Rev Genet. 2010 Mar, pp.(181-190)

Marraffini LA \& Sontheimer EJ. (2010). Self versus non-self discrimination during CRISPR RNA-directed immunity. Nature 2010, pp.(568-571)

Medzhitov R, Janeway Jr.C. (2000). The toll receptor family and microbial recognition. Trends Microbiol 2000, 10, pp.(452-456), 9310916

Mendizabal JL, LLamazares S, Rossell D, \& Gonzalez C. (2010). Ectopic Expression of Germline Genes Drives Malignant Brain Tumor Growth in Drosophila. Science. 2010, 330, pp.(1824-1827), 0404511

Miller DJ, Hemmrich G, Ball EE, Hayward DC, Khalturin K, Funayama N, Agata K, Bosch TC. (2007). The innate immune repertoire in cnidaria-ancestral complexity and stochastic gene loss. Genome Biol 2007;8. pp.(1-13), 100960660

Ngoi SM, Sylvester FA, \& Vella AT. (2011). The role of microbial byproducts in protection against immunological disorders and the hygiene hypothesis. Discov Med. 2011, 12.66, pp.(405-12), 101250006

Pancer Z. (2000). Dynamic expression of multiple scavenger receptor cysteine-rich genes in coelomocytes of the purple sea urchin. Proc Natl Acad Sci. 2000, 97, pp.(13156-61), 7505876

Parrinello. (2010). "Has innate immunity evolved through different routes?" 85-7. Phys Life Rev 2010, 7, pp.(83-84), 101229718

Perlovsky L. 2010; Cooper, E.L. Self/not self, innate immunity, danger, cancer potential. Phys Life Rev, 2010 pp.(55-78), 101229718

Powell AE, Nicotra ML, Moreno MA, Lakkis FG, Dellaporta SL, Buss LW. (2007). Differential effect of allorecognition loci on phenotype in Hydractinia symbiolongicarpus (Cnidaria: Hydrozoa). Genetics. 2007, 177, pp.(2101-2107) 0374636

Pradeu T. and E.D. Carosella. (2004). Critical analysis of the immunological self/non-self model and of its implicit metaphysical foundations. 2004, 325, 5, pp.(481-492), 101140040

Pradeu T. and E.D. Carosella. (2006). On the definition of a criterion of immunogenicity. Proc Natl Acad Sci USA, 2006, 103, 47, pp. (17858-1786), 7505876

Read RD. (2011). Drosophila melanogaster as a model system for human brain cancers. Glia. 2011, 59., pp.(1364-76), 8806785

Ribatti D. (2009). Sir Frank Macfarlane Burnet and the clonal selection theory of antibody formation, Clin Exp Med 2009, December, 4, pp.(253-258), 100973405 
Riddihough, G. (2011). Structural biology Seahorse Versus Pathogen. Nat. Struct. Mol. Biol, 2011, pp.(10), 18, 10.1038/nsmb.2019 (2011).

Sasake Ni, Ogasawara M, Sekiguchi, T, Kusumoto S, \& Satake H. (2011). Prototypes with Hybrid Functionalities of Vertebrate Toll-Like Receptors. Fish Shellfish Immunol. 2011, 30, pp.(653-660), 2985121R

Silverstein AM. A history of immunology. San Diego: Academic Press; 1989.

Sun S-C, Lindstrom I, Boman HG, Faye I, \& Schmidt O. (1990). Hemolin: An insect-immune protein belonging to the immunoglobulin superfamily. Science. 1990, 250, pp.(172932), 0404511

Tauber AI, Chernyak L. (1991). Metchnikoff and the origins of immunology: From metaphor to theory. New York: Oxford University Press; 1991.

Theodor JL. (1970). Distinction between "self" and "not-self" in lower invertebrates. Nature 1970,227, pp.(690-692), 0410462

Tracey KJ. (2011). Ancient Neurons Regulate Immunity. Science. 2011, May, 332, 6030 pp.(673-674), 0404511

Van der Oost J, Jore MM, Westra ER, Lundgren M, Brouns SJ. CRISPR-based adaptive and heritable immunity in prokaryotes. Trends Biochem Sci. 2009, Aug, 34, 8, pp.(401407), 7610674

Walther BA, Ewald PW. Pathogen survival in the external environment and the evolution of virulence. Biol Rev Camb Philos Soc. 2004, Nov, 79, 4, pp.(849-869), 0414576

Walker CW, Van Beneden RJ, Muttray AF, Böttger SA, Kelley ML, Tucker AE, \& Thomas WK. (2011). Superfamily proteins in marine bivalve cancer and stress biology. Adv Mar Biol. 2011, 59, pp.(1-36), 0370431

Watson FL, Püttmann-Holgado R, \& Thomas F. (2005). Immunology: Extensive diversity of Ig-superfamily proteins in the immune system of insects. Science. 2005, 309. pp.( 1874-8), 0404511

Wiedenheft, B., Lander, G.C., Zhou, K., Jore, M.M., Brouns, S.J.J., van der Oost, J., Doudna, J.A., \& Nogales E., Structures of the RNA-guided surveillance complex from a bacterial immune system. Nature 477, pp.(486-489), 0410462

Wiens M, Korzhev M, Perovic-Ottstadt S, Luthringer B, Brandt D, Klein S, Müller WE: Tolllike receptors are part of the innate immune defense system of sponges (demospongiae: Porifera). Mol Biol Evol. 2007, 24. pp.(792-804), 8501455

Wikipedia CRISPR. http://en.wikipedia.org/wiki/CRISPR

Wikipedia Prokaryotes. http://en.wikipedia.org/wiki/Eukaryote

Wu X \& Ruykun G. (2010). Cancer. Germ cell genes and cancer..Science. 2010, 330 pp.(17611762), 0404511

Zhang S-M, Adema CM, Kepler TB, \& Loker ES. (2004). Diversification of Ig superfamily genes in an invertebrate. Science. 2004, 305, pp.(251-4). 0404511

Zhang L., Li L., \& Zhang G (2011). Crassostrea gigas Toll-like receptor and comparative analysis of TLR pathway in invertebrates. Fish Shellfish Immunol. 2011, 2, pp.(65360), 9505220 


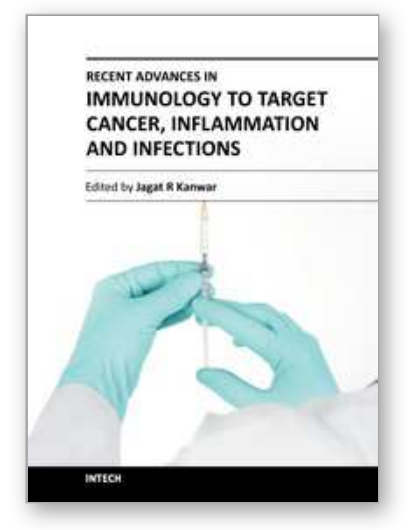

\author{
Recent Advances in Immunology to Target Cancer, Inflammation \\ and Infections \\ Edited by Dr. Jagat Kanwar
}

ISBN 978-953-51-0592-3

Hard cover, 520 pages

Publisher InTech

Published online 09, May, 2012

Published in print edition May, 2012

Immunology is the branch of biomedical sciences to study of the immune system physiology both in healthy and diseased states. Some aspects of autoimmunity draws our attention to the fact that it is not always associated with pathology. For instance, autoimmune reactions are highly useful in clearing off the excess, unwanted or aged tissues from the body. Also, generation of autoimmunity occurs after the exposure to the non-self antigen that is structurally similar to the self, aided by the stimulatory molecules like the cytokines. Thus, a narrow margin differentiates immunity from auto-immunity as already discussed. Hence, finding answers for how the physiologic immunity turns to pathologic autoimmunity always remains a question of intense interest. However, this margin could be cut down only if the physiology of the immune system is better understood. The individual chapters included in this book will cover all the possible aspects of immunology and pathologies associated with it. The authors have taken strenuous effort in elaborating the concepts that are lucid and will be of reader's interest.

\title{
How to reference
}

In order to correctly reference this scholarly work, feel free to copy and paste the following:

Edwin L. Cooper (2012). Adaptive Immunity from Prokaryotes to Eukaryotes: Broader Inclusions Due to Less Exclusivity?, Recent Advances in Immunology to Target Cancer, Inflammation and Infections, Dr. Jagat Kanwar (Ed.), ISBN: 978-953-51-0592-3, InTech, Available from: http://www.intechopen.com/books/recentadvances-in-immunology-to-target-cancer-inflammation-and-infections/adaptive-immunity-from-prokaryotesto-eukaryotes-broader-inclusions-due-to-less-exclusivity

\section{INTECH}

open science | open minds

\section{InTech Europe}

University Campus STeP Ri

Slavka Krautzeka 83/A

51000 Rijeka, Croatia

Phone: +385 (51) 770447

Fax: +385 (51) 686166

www.intechopen.com

\section{InTech China}

Unit 405, Office Block, Hotel Equatorial Shanghai

No.65, Yan An Road (West), Shanghai, 200040, China 中国上海市延安西路65号上海国际贵都大饭店办公楼405单元

Phone: +86-21-62489820

Fax: +86-21-62489821 
(C) 2012 The Author(s). Licensee IntechOpen. This is an open access article distributed under the terms of the Creative Commons Attribution 3.0 License, which permits unrestricted use, distribution, and reproduction in any medium, provided the original work is properly cited. 